\title{
Hepatic drug acetylation and oxidation: effects of aging in man
}

\author{
FATIMA FARAH， WENDY TAYLOR, MICHAEL D RAWLINS, OLIVER JAMES
}

British Medical fournal, 1977, 2, 155-156

\section{Summary}

The half lives of acetanilide and isoniazid ("model" substrates for oxidation and acetylation respectively) were measured in populations of young (aged 20-35 years) and elderly (aged over 65 years) people. Whereas acetanilide half lives were significantly longer in the elderly, isoniazid half lives were distributed similarly in both populations. The results suggest that liver function does not decline uniformly with age and that heterozygotes for acetylation do not possess survival advantages during their middle years of life.

\section{Introduction}

Microsomal oxidation within the liver is the metabolic pathway whereby many psychotropic drugs, anticonvulsants, oral anticoagulants, and oral antidiabetic agents are inactivated. ${ }^{1}$ It seems to be largely under polygenic control :' diminished capacity to oxidise drugs is associated with an increased incidence of adverse reactions. ${ }^{3}+$ Hepatic acetylation of drugs such as isoniazid, procainamide, hydrallazine, dapsone, and many sulphonamides is under polymorphic control ${ }^{5}$ and occurs via a non-microsomal enzyme pathway. Populations are sharply divided into "fast" or "slow" acetylators: adverse reactions to most acetylated drugs ${ }^{1}$ occur more often in slow acetylators.

Epidemiological evidence suggests that the incidence of adverse drug reactions increases with advancing years. ${ }^{6}$; In particular, the elderly seem to be especially intolerant of benzodiazepines. "Such changes in patients' responses to drugs may be due to altered kinetics or to enhanced sensitivity of target organs. ${ }^{9}$ Several studies have indicated that aging is associated with diminished hepatic microsomal oxidation. ${ }^{10} 11$ The influence of aging on other pathways of drug metabolism, however, is less clear. We therefore compared hepatic oxidation with acetylation in groups of young and elderly subjects to investigate whether diminished metabolism of drugs by the liver is a generalised phenomenon with increasing age.

\section{Subjects and methods}

The subjects for these studies were aged either under 35 years (the young group) or over 65 years (the elderly group). The young group were drawn from medical students or laboratory staff; the elderly group were recruited from patients attending the department of geriatric medicine, Newcastle General Hospital. None of the subjects were receiving drugs known to interfere with either acetylation or oxidation or had a history of heavy alcohol consumption. Routine

Departments of Pharmacological Sciences (Clinical Pharmacology) and Medicine (Geriatrics), University of Newcastle upon Tyne, Newcastle NE1 7RU

FATIMA FARAH, MRCP, research registrar WENDY TAYLOR, BMEDSC, medical studen MICHAEL D RAWLINS, FRCP, professor of clinical pharmacology OLIVER JAMES, MRCP, reader in medicine (geriatrics) biochemical liver function tests were performed on all the participants (serum bilirubin, alkaline phosphatase, aspartate aminotransferase, and albumin concentrations were measured). Serum total bile acid levels, a possible marker of liver dysfunction, ${ }^{12}$ were also measured. All these values were within the $95 \%$ confidence intervals of the laboratory normal values. The study was approved by the local ethical committees, and all the subjects gave their informed consent.

Acetylation rates were estimated from the elimination half lives of isoniazid after a fasting oral dose of $10 \mathrm{mg} / \mathrm{kg}$ body weight (to the nearest $50 \mathrm{mg}$ ); venous blood was withdrawn $0,1 \frac{1}{2}, 2 \frac{1}{2}, 3 \frac{1}{2}, 4 \frac{1}{2}$, and 6 hours after dosing, with the subjects remaining seated throughout the investigation. Oxidation was assessed from the elimination half lives of acetanilide after a fasting dose of $50 \mathrm{mg} / \mathrm{kg}$ metabolically active mass (body weight 0.7 ); venous blood samples were withdrawn 0,1 , $2,3,4$, and 6 hours after dosing.

Plasma was stored at $-20^{\circ} \mathrm{C}$ until analysis by spectrophotometry (for isoniazid) ${ }^{13}$ or gas-liquid chromatography (for acetanilide). ${ }^{14}$ Half lives were calculated by least-squares regression analysis of the terminal monoexponential part of the plasma concentration time curves. (Previous studies with both acetanilide ${ }^{15}$ and isoniazid ${ }^{16}$ have shown the reproducibility of these methods.) The statistical significance between means was assessed by Wilcoxon's rank sum analysis.

\section{Results}

Isoniazid half lives were measured in 23 young and 27 elderly people. There was a bimodal distribution in both groups (see table) There was no difference $\left(\chi^{2}=0.277 ; P<0.1\right)$ in the proportions of fast acetylators in each group ( $44 \%$ of the young; $41 \%$ of the elderly). Mean half lives did not differ with age in either fast or slow acetylators (half lives for fast acetylators were 1.4 hours in the young and 1.5 hours in the elderly; for slow acetylators they were 3.7 hours in the young and $4 \cdot 2$ hours in the elderly), and the antimode (2.5-2.9 hours) was the same for both.

Acetanilide half lives were estimated in 19 young and 24 elderly people. In both groups half lives were continuously distributed (see table), ranging from $0.84-2.5$ hours in the young and 0.64-4.31 hours in the elderly. Mean half lives, however, were significantly $(P<0.01)$ shorter in the young group ( 1.45 hours $v 2.07$ hours).

TABLE-Distribution of plasma half lives of isoniazid and acetanilide in elderly and young subjects

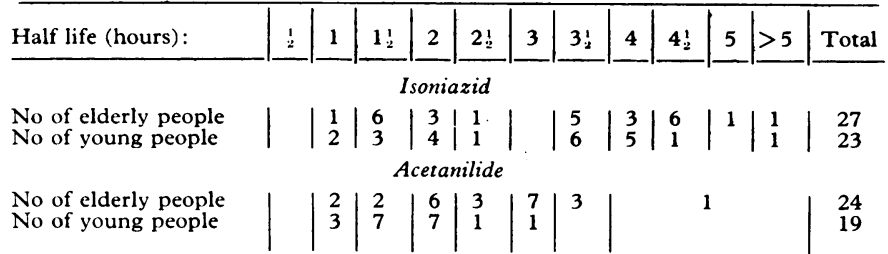

\section{Discussion}

The use of half life estimates of acetanilide and isoniazid as "model" substrates in assessing oxidation and acetylation in man has been validated $:^{15} 17$ both drugs are completely absorbed, uniformly distributed, poorly bound to plasma proteins, and eliminated extensively by a single metabolic pathway. The plasma half lives of both are reproducible, so that they are particularly suitable for assessing liver metabolic functions without 
such complicating factors as variable absorption or distribution.

Two important features emerge from this study. Firstly, our findings confirm observations ${ }^{1011}$ of an age-related decline in microsomal oxidation rates in man. Secondly, they show that in a population exhibiting this decline acetylation does not change with age. Thus, there are pharmokinetic grounds in the elderly for reducing the dose of drugs that are metabolised by oxidation, but this does not seem to apply to drugs metabolised by acetylation. Indeed, in so far as the latter pathway is concerned, not only was there no observed difference in acetylator phenotype in the two groups but there was also no apparent difference within the phenotypes, or in antimodes between the populations. These findings do not therefore support the hypothesis that heterozygotes for acetylation have a survival advantage to old age. Nor do they support the hypothesis that there is a general decline of liver function with advancing age in man. ${ }^{1 \times}$

We thank Mrs L Pulmann and Mr D B Henderson for technical help; Dr A J Cassells-Smith and the department of clinical biochemistry, Newcastle General Hospital, for undertaking the routine laboratory investigations; colleagues in the department of geriatric medicine, Newcastle General Hospital; and the Newcastle Area Health Authority (Teaching) for financial support.

\section{References}

1 Smith, S E, and Rawlins, M D, V'ariability in Human Drug Response. London, Butterworth, 1973.

2 Whittaker, J A, and Evans, D A P, British Medical fournal, 1970, 4, 323

3 Åsberg, M, et al, British Medical fournal, 1970, 4, 18

- Kutl, H, et al, Archives of Neurology, 1964, 11, 642.

' Evans, D A P, Manley, K A, and McKusick, V A, British Medical fournal, $1960,42,485$

' Seidl, L G, et al, Bulletin of the fohns Hopkins Hospital, 1966, 119, 299.

i Hurwitz, N, British Medical fournal, 1969, 1, 549.

${ }^{8}$ Evans, J G, and Jarvis, E H, British Medical fournal, 1972, 4, 487.

${ }^{9}$ Rawlins, M D, British Medical fournal, 1974, 4, 91.

${ }^{10}$ O'Malley, K, et al, British Medical fournal, 1971, 3, 607.

${ }^{11}$ Vestal, R E, et al, Clinical Pharmacology and Therapeutics, 1975, 18, 425.

12 Javitt, N B, in Diseases of the Liver, ed L Schiff, p 111. Philadelphia, Lippincott, 1975.

${ }^{13}$ Maher, J T, et al, American Review of Tuberculosis and Pulmonary Diseases, 1957, 76, 852

14 Henderson, D B, unpublished.

15 Cunningham, J L, Bullen, M F, and Evans, D A P, European fournal of Clinical Pharmacology, 1974, 7, 461.

16 Taylor, W, Batchelor of Medical Sciences thesis. University of Newcastle upon Tyne, 1976

1: Mitchell, J R, Clinical Pharmacology and Therapeutics, 1975, 18, 70.

is Skaunic, V, Nerad, V, and Skaunicova, J, Gerontologia Clinica, 1968, 10, 43

(Accepted 11 May 1977)

\title{
Growth hormone, insulin, and prolactin secretion in anorexia nervosa and obesity during bromocriptine treatment
}

\author{
A D B HARROWER, P L YAP, ISOBEL M NAIRN, H J WALTON, J A STRONG, A CRAIG
}

British Medical fournal, 1977, 2, 156-159

ginally raised in two obese subjects, fell significantly in both groups during treatment. We observed no consistent weight changes in either group.

\section{Summary}

We studied secretion of growth hormone (GH), insulin, and prolactin in eight women with anorexia nervosa and nine women with refractory obesity before and during treatment with bromocriptine, $10 \mathrm{mg} / \mathrm{day}$.

In the anorexic patients the raised plasma GH concentrations occurring during an oral glucose tolerance test fell significantly while on bromocriptine treatment, but there was no change in plasma insulin or blood glucose concentrations. In the obese patients, however, plasma GH concentrations remained low during the oral glucose tolerance test, and were not modified by bromocriptine. Blood glucose and plasma insulin concentrations were also unchanged. Plasma GH and plasma 11-hydroxycorticosteroid responses to insulin-induced hypoglycaemia were unaffected. Serum prolactin concentrations which were raised in five anorexic patients and mar-

Metabolic Unit, Departments of Medicine and Psychiatry, Western General Hospital, Edinburgh EH4 2XU

A D B HARROWER, MRCP, senior registrar

$P$ L YAP, MB, CHB, senior house officer

ISOBEL M NAIRN, BSC, senior biochemist, metabolic unit

H J WALTON, MD, FRCPSYCH, professor and head of department of psychiatry

J A STRONG, MD, FRCP, professe $r$ of medicine and consultant physician

Searle Diagnostic, High Wycombe, Bucks HP12 4HL

A CRAIG, PHD, divisional manager, medical laboratory services

\section{Introduction}

Bromocriptine raises the blood concentration of growth hormone $(\mathrm{GH})$ in normal subjects, ${ }^{1}$ while depressing the raised concentrations of $\mathrm{GH}$ in patients with acromegaly." 3 Most patients with anorexia nervosa have raised fasting concentrations of $\mathrm{GH}$ that fail to decrease during an oral glucose tolerance test, and may indeed show a paradoxical rise as in some cases of acromegaly. ${ }^{+}$In obesity, however, plasma GH concentrations are low ${ }^{5}$ and do not show the post-absorptive peak seen in normal subjects. ${ }^{6}$ These anomalous GH responses prompted us to study the effect of bromocriptine on $\mathrm{GH}$ and insulin secretion in patients with anorexia nervosa and refractory obesity.

Serum prolactin concentrations have been reported to be normal $^{*}{ }^{*}$ or increased ${ }^{9}$ in patients with anorexia nervosa, but there is no information about prolactin concentrations in obese people. We therefore also investigated the effect of bromocriptine on serum prolactin concentrations in both conditions. We monitored the weights of both groups of patients closely since some overweight patients with galactorrhoea have been shown to revert to their normal weight while on treatment with bromocriptine. ${ }^{11}$

\section{Patients and methods}

We studied eight women with typical anorexia nervosa. Six of them were under our care for the first time, and two (cases 1 and 2) had 